\title{
Traumatic lens dislocation
}

\author{
Sangil Lee ${ }^{1 *}$, Alison Hayward ${ }^{2}$ and Venkatesh R Bellamkonda ${ }^{3}$
}

\begin{abstract}
Background: Point-of-care ultrasound has been widely used by clinicians, particularly those in emergency care settings.

Findings: A 44-year-old male who sustained a blunt ocular trauma resulting in acute vision loss due to posterior dislocation of the crystalline lens identified by point-of-care ultrasound is described in the study. Point-of-care ultrasound with a high linear-array transducer was used to gain the sagittal view of the eye globe.
\end{abstract}

Conclusions: Point-of-care ultrasound can be a useful tool to make a rapid diagnosis of ocular emergency including lens abnormality.

Keywords: Point-of-care ultrasound; Lens dislocation; Ocular trauma

\section{Findings}

\section{Case synopsis}

A 44-year-old man was fixing his mountain bike when the shock absorber broke apart, shooting a cap which struck him in the left eye. Intense pain and vision loss developed. Initial vital signs were stable (BP $117 / 79 \mathrm{mmHg}$, pulse $80 \mathrm{bpm}$, respiratory rate 16 breaths per minute, oxygen saturation $99 \%$ on room air). Physical exam revealed that the patient had a laceration to his superior eyelid, a subconjunctival hemorrhage, and a hyphema. The deformity of the left pupil was noticed. He was only able to perceive light from the affected eye. Head and neck exams were otherwise unremarkable. After topical anesthetics were given, a $13-6-\mathrm{MHz}$ linear-array ultrasound probe was applied using a closed-eye technique. Point-of-care ultrasound and CT imaging of the patient are shown in Figs. 1 and 2. CT showed no skull fracture, facial fracture, or intracranial abnormality. Diagnosis of traumatic lens dislocation was confirmed. This patient was reimmunized against tetanus, given antibiotics, provided an eye shield, and then taken to the operating room for management by ophthalmology. Exploration showed posterior lens dislocation, upper lid laceration without globe rupture. Postoperatively, intraocular pressure rose to $38 \mathrm{mmHg}$ and Timolol, Brimonidine were started. The patient was

\footnotetext{
* Correspondence: Lee.Sangil@mayo.edu

${ }^{1}$ Department of Emergency Medicine, Mayo Clinic Health System, 1453

Marsh Street, Mankato, MN 56001, USA

Full list of author information is available at the end of the article
}

released on postoperative day three. A consent was obtained from the patient.

\section{Discussion}

Point-of-care ultrasound demonstrates a displaced lens in the posterior chamber (Fig. 1), which is confirmed by CT scan (Fig. 2). Lens dislocation is a rare complication of head injuries. However, trauma is the most common cause of lens dislocation [1]. Blunt force in anteroposterior direction leads to equatorial expansion, which disrupts the zonular fibers and dislocates the lens [2]. Connective tissue disorders and primary ocular disorders should be considered in the absence of trauma. Patients with Marfan's syndrome have better prognosis than those with traumatic lens displacement; however, for both conditions, the displacement of the lens is a threat to vision [1].

Point-of-care ultrasound can quickly establish the diagnosis and prompt ophthalmology consultation without CT results. Ultrasound is used primarily to evaluate internal structures of the globe, especially when direct visualization is difficult due to cataracts or hemorrhage. It can help to detect choroidal or retinal detachment, and also has some retro-ocular applications. A closed-eye technique is performed by placing a high linear-array ultrasound transducer to the patient's closed eyelid. A large amount of water soluble gel is used to avoid direct contact with the eyelid. The globe should be evaluated in sagittal and transverse planes. The dilatation of pupils and the use 


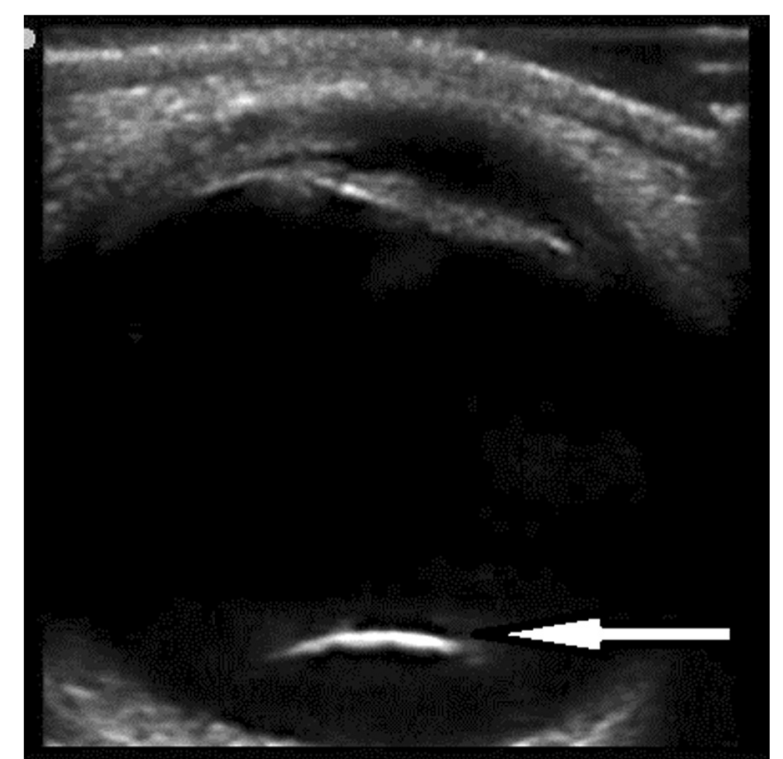

Fig. 1 Sagittal view of left eye globe showing floating lens in the posterior chamber (white arrow)

of ophthalmoscope can be obviated by point-of-care ultrasound.

The complications of lens dislocation include secondary glaucoma, retinal detachment, cataract, and vision loss [3]. Surgical repair is often the treatment of choice, including repositioning, explanting, or exchanging the displaced intraocular lens particularly when dislocation is a result of trauma [4]. Our patient developed secondary glaucoma, proliferative vitreoretinopathy and required lens removal.

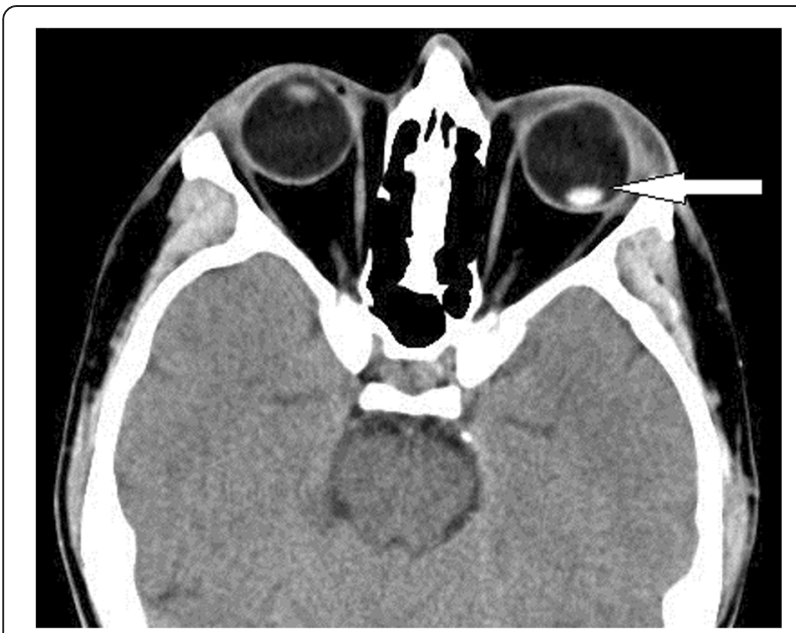

Fig. 2 CT image corresponding to point-of-care ultrasound showing dislocated lens (white arrow)

\section{Teaching pearls}

1. Traumatic lens dislocation is one of the differentials for irregular pupil after trauma.

2. Point-of-care ultrasound is an excellent diagnostic modality for eye pathology.

3. Contraindication for ultrasound is globe rupture.

\section{Abbreviation}

CT: Computed tomography.

\section{Competing interests}

The authors declare that they have no competing interests.

\section{Authors' contributions}

$S L, A H$, and $V B$ reviewed the case and images. SL drafted, revised, and submitted the manuscript. AH prepared the manuscript and reviewed the images. VB revised the manuscript and reviewed the images. All authors 1) have made substantial contributions to conception and design, acquisition of data, or analysis and interpretation of data; 2) have been involved in drafting the manuscript or revising it critically for important intellectual content; 3 ) have given final approval of the version to be published; and 4) agree to be accountable for all aspects of the work in ensuring that questions related to the accuracy or integrity of any part of the work are appropriately investigated and resolved.

\section{Author details}

${ }^{1}$ Department of Emergency Medicine, Mayo Clinic Health System, 1453 Marsh Street, Mankato, MN 56001, USA. ${ }^{2}$ Department of Emergency Medicine, Yale University, 464 Congress Ave, Ste 260, New Haven, CT 06519-1315, USA. ${ }^{3}$ Department of Emergency Medicine, Mayo Clinic, 200 2nd Street, Rochester, MN 55901, USA.

Received: 26 February 2015 Accepted: 2 May 2015

Published online: 27 May 2015

\section{References}

1. Jarrett WH. Dislocation of the lens: a study of 166 hospitalized cases. Arch Ophthalmol. 1967:78(3):289-96.

2. Marcus DM, Topping Jr TM, Frederick AR. Vitreoretinal management of traumatic dislocation crystalline lens. Int Ophthalmol Clin. 1995;35(1):139-50.

3. Wang HE. Diagnosis of traumatic lens dislocations. J Emerg Med. 2000;19(1):73-4.

4. Jones WL. Traumatic injury to the lens. Optom Clin. 1991;1 (2):125-42.

\section{Submit your manuscript to a SpringerOpen ${ }^{\circ}$ journal and benefit from:}

- Convenient online submission

$\checkmark$ Rigorous peer review

- Immediate publication on acceptance

- Open access: articles freely available online

- High visibility within the field

- Retaining the copyright to your article

Submit your next manuscript at springeropen.com 